\title{
Confining Properties of Carbonated Dogger Caprocks (Parisian Basin) for $\mathrm{CO}_{2}$ Storage Purpose
}

\author{
P. Carles ${ }^{1 *}$, P. Bachaud ${ }^{2}$, E. Lasseur ${ }^{3}$, P. Berne ${ }^{2}$ and P. Bretonnier ${ }^{1}$ \\ 1 Institut français du pétrole, IFP, 1-4 avenue de Bois-Préau, 92852 Rueil-Malmaison Cedex - France \\ 2 CEA, LITEN, L2T, 38054 Grenoble - France \\ 3 BRGM, 3 avenue Claude Guillemin, BP 6009, 45060 Orléans Cedex 2 - France \\ e-mail: patricia.carles@airliquide.com - pierre.bachaud@cea.fr - e.lasseur@brgm.fr - philippe.berne@cea.fr - pierre.bretonnier@ifp.fr \\ * Corresponding author - now in Air Liquide
}

Résumé - Propriétés de confinement des couvertures du Dogger carbonaté (Bassin de Paris) dans l'optique du stockage de $\mathbf{C O}_{2}$ - Le projet Géocarbone-Intégrité, financé par l'Agence Nationale de la Recherche (ANR) de 2006 à 2008, vise à développer les connaissances et les techniques nécessaires à la prévision de l'efficacité et la sécurité du confinement sur le long terme des stockages géologiques de $\mathrm{CO}_{2}$. La première tâche a été de caractériser à l'échelle pétrographique, les faciès carbonatés du sommet du Dogger appartenant aux formations des Calcaires du Comblanchien et de la Dalle Nacrée, situées immédiatement au-dessus des niveaux réservoirs retenus comme potentiels sites de stockage. Une étude pétrophysique précise des faciès de couvertures potentielles est réalisée. La porosité, la distribution de taille de pores et la perméabilité sont déterminées en utilisant des méthodes adaptées à des milieux très peu perméables (<10 microDarcy). Les perméabilités sont mesurées à l'azote, à l'hélium et à la saumure sous pression de confinement avec la méthode stationnaire et la méthode transitoire. Les porosités sont faibles et varient de 2 à $9 \%$ suivant le faciès, et les perméabilités en monophasique varient de 0,3 à 20 microDarcy. Le fait d'utiliser plusieurs techniques de mesure de porosité et perméabilité permet d'évaluer l'incertitude des résultats. La pression capillaire de seuil est estimée par les courbes d'injection de mercure (Purcell). L'estimation à partir des courbes de Purcell est sujette aux incertitudes (choix des tensions interfaciales et du point d'entrée du mercure) et ne remplace donc pas une mesure directe de pression de seuil. La pression de seuil est donc aussi mesurée sur carotte en conditions in situ avec de l'azote $\left(\mathrm{N}_{2}\right)$ et du dioxyde de carbone $\left(\mathrm{CO}_{2}\right)$, pour voir l'effet du $\mathrm{CO}_{2}$ sur la pression d'entrée par rapport à un gaz neutre. Deux méthodes sont utilisées, la méthode classique par paliers de pression et la méthode dynamique. La méthode dynamique est basée sur la réduction de débit de saumure en sortie de l'échantillon lorsque le gaz commence à pénétrer à l'entrée de l'échantillon saturé en saumure. Chacune de ces méthodes possède des avantages et des limites d'application mis en exergue dans le cadre de cette étude. Pour le système $\mathrm{CO}_{2}$ /saumure les valeurs de pressions de seuil mesurées vont de 0,4 à 22 bar suivant les faciès. Les valeurs de $P_{t h}$, même pour le faciès le plus compact, sont probablement trop faibles pour que l'on puisse exclure une pénétration du $\mathrm{CO}_{2}$ dans la roche de couverture. Cette constatation n'interdit toutefois pas d'envisager un stockage de $\mathrm{CO}_{2}$, dans la mesure où on peut montrer que la perméabilité de la couverture est suffisamment faible, et son épaisseur suffisamment grande, pour que cette pénétration reste limitée malgré le maintien de la surpression sur la durée.

\footnotetext{
Abstract - Confining Properties of Carbonated Dogger Caprocks (Parisian Basin) for $\mathrm{CO}_{2}$ Storage Purpose - The Géocarbone-Intégrité project, funded by ANR (Agence Nationale de la Recherche) from 2006 to 2008, has the overall objective of gaining knowledge and technology to predict storage integrity and safety for long term geological $\mathrm{CO}_{2}$ sequestration. The aim of this study (Sect. 1 and 2 of the project)
} 
is to evaluate the sealing capacities of the carbonated Dogger caprocks located on top of the reservoirs where $\mathrm{CO}_{2}$ could be injected for storage purposes in the Parisian Basin. A petrographic analysis is done on 3 different cores from geological formations of the "Comblanchien and Dalle Nacrée" tight carbonates facies. At the same time, a petrophysical study of these facies is performed. Porosity, pore size distribution and permeability are determined using special devices adapted to low permeability and tight rocks $(<10$ microDarcy). Permeabilities are measured with nitrogen, helium and brine under confining pressure using unsteady-state and steady-state methods. Porosities are low and vary from 2 to $9 \%$, depending on the facies, and single-phase permeabilities vary from 0.3 to 20 microDarcy. Using different techniques of porosity and permeability measurement allows evaluation of the uncertainties. The sealing efficiency of a caprock towards $\mathrm{CO}_{2}$ is primarily controlled by the threshold capillary pressure at in situ conditions. This threshold pressure is first estimated by mercury injection (HPMI). It is also directly measured on core samples at in situ conditions with Nitrogen $\left(\mathrm{N}_{2}\right)$ and Carbon dioxide $\left(\mathrm{CO}_{2}\right)$ (to see the effect of $\mathrm{CO}_{2}$ compared to a neutral gas on the threshold pressure). Two different techniques, described in detail in this article, are used: the dynamic method and the pressure step method. For the $\mathrm{CO}_{2}$ /brine system, measured threshold capillary pressures vary from 0.4 bar to 22 bar, depending on the facies. The $P_{\text {th }}$ values, even for the tighter facies (CH106), are probably too low to exclude penetration of $\mathrm{CO}_{2}$ into the caprock. This however does not rule out storage of $\mathrm{CO}_{2}$, as long as it can be proved that the permeability of the caprock is low enough and its thickness large enough to limit the extent of this penetration even though overpressure is maintained for a long period.

\section{DEFINITIONS, ACRONYMS, ABBREVIATIONS}

HPMI High Pressure Mercury Injection

IFT Interfacial tension

$K_{g} \quad$ Gas permeability

$K_{w} \quad$ Water permeability

NMR Nuclear Magnetic Resonance

$P \quad$ Pressure

$P_{C} \quad$ Confining pressure

$P_{t h} \quad$ Threshold pressure

$\Delta P_{t} \quad$ Total pressure drop

$\Delta P_{n w} \quad$ Non-wetting fluid region pressure drop

$\Delta P_{w} \quad$ Wetting fluid region pressure drop

PU Porosity Unit

Qw Brine flow rate

RT Rotary Table

T Temperature

$\Phi \quad$ Porosity

\section{INTRODUCTION}

Large-scale subsurface storage of anthropogenic carbon dioxide in deep saline aquifers is considered as a potential technology for stabilizing greenhouse gas concentration in the atmosphere $[1,2]$. The containment of $\mathrm{CO}_{2}$ within the injection unit and leakage avoidance are essential for $\mathrm{CO}_{2}$ Capture and Storage (CCS). Effective $\mathrm{CO}_{2}$ containment is achieved by tight caprock formations overlying the aquifer in which the $\mathrm{CO}_{2}$ will be injected. It is essential to know the caprock seal capacities to prevent carbon dioxide migration into shallow freshwater aquifers and ultimately to the atmosphere [3].
The aim of this study is to evaluate the sealing capacities of the carbonated Dogger caprocks for $\mathrm{CO}_{2}$ storage purpose in the Paris Basin. The first potential caprocks situated above the potential formation for $\mathrm{CO}_{2}$ storage are two carbonated formations: the Comblanchien limestone (upper Bathonian) and the Dalle nacrée formation (Callovian). A specific petrophysical study was performed simultaneously on these facies. Porosity, pore size distribution and permeability are determined using devices adapted to low permeability and tight rocks $(<10$ microDarcy). Permeability is measured with nitrogen and helium under confining pressure (60 and 90-110 bar) using unsteady-state and steady-state methods [4]. All measurements are corrected for the Klinkenberg effect [5]. Permeability is also measured with brine under higher confining pressure ( $250 \mathrm{bar}$ ) using the steady-state method. The sealing efficiency of a caprock towards $\mathrm{CO}_{2}$ is primarily controlled by the threshold capillary pressure at in situ conditions. This threshold pressure is first estimated by High Pressure Mercury Injection (HPMI). It is also directly measured on core samples under confining pressure with Nitrogen and Carbon dioxide to see the effect of $\mathrm{CO}_{2}$ compared to a neutral gas, by using two different techniques: the dynamic method [6] and the pressure step method. The dynamic method is based on a flow rate reduction when the $\mathrm{CO}_{2}$ starts entering the sample. Each method has strengths and weaknesses and application limits that are explained in this study.

\section{SAMPLE PETROGRAPHY}

The samples studied come from 3 cores (CH106, CH107 and CH109) from an oilfield called Charmottes, $100 \mathrm{~km}$ southeast from Paris. Lithostratigraphically, CH106 samples are part of 
the Comblanchien limestones formation, $\mathrm{CH} 109$ samples are from the Dalle Nacrée formation, and $\mathrm{CH} 107$ samples are part of the transition zone between these two formations.

CH106 samples are from a lagoon type facies (Facies 4 of Lasseur and Le Nindre, this volume) [7]. These facies are very tight mudstones to wackestone-packstones with algal fabric. Gasteropodes, ostracodes and benthic foraminifers as well as frequent lithoclasts are common. Their micritic matrix is recrystallized into microsparite. Secondary fractures are in most cases filled by sparite. These facies show very low porosity (2-3\% and less). Samples from CH107 correspond to a shallow water facies in more or less confined environments (Facies 3 of Lasseur and Le Nindre, this volume). These facies vary from wackestone to packstone and are highly heterogenous vertically, mostly because of a relatively complex diagenetic history. Their micritic matrix can be strongly recrystallized into sparite. Dissolution, secondary filling by dolomite crystallization and clay precipitation, is common along stylolithes and bioturbations. From optical estimations using thin sections, these facies have a mean porosity of $8 \%$. Samples from $\mathrm{CH} 109$ core vary from oolithic shoals, facies $1 \mathrm{~b}$ (109-1-2aH and 109-2-2aH) to pre-reef deposits facies 1c (109-2-1aV). Facies $1 \mathrm{~b}$ are oolithic grainstone-packstone type. Facies 1c are grainstone-rudstones with highly diverse faunas, and cementation is less pronounced than in facies $1 \mathrm{~b}$. Figure 1 shows SEM photos of 3 samples representative of the studied facies. Mineralogical analysis reveals various proportions of calcite, ankerite, quartz, clays (essentially mica, illite and kaolinite) and gypsum in the studied samples (Tab. 1).

TABLE 1

Mineralogical composition (in weight fraction) of the studied samples

\begin{tabular}{c|c|c|c|c|c|c}
\hline Samples & Calcite & Ankerite & Quartz & Clays & Pyrite & Gypsum \\
\hline $106-5-2$ & $95 \%$ & $4 \%$ & Traces & - & - & - \\
\hline $107-1-4$ & $40 \%$ & $30 \%$ & $20 \%$ & Traces & - & Traces \\
\hline $109-2-1$ & $90 \%$ & $5 \%$ & Traces & - & $5 \%$ & Traces \\
\hline
\end{tabular}

\section{PETROPHYSICAL CHARACTERIZATION}

\subsection{Sample Selection and Size}

Among the 3 available cores (CH106, $\mathrm{CH} 107$, and $\mathrm{CH} 109$ ), we selected samples after coring by using X-ray CT-scan images (Fig. 2) to ensure the integrity, representativity and homogeneity of the samples. These samples are of three types:

- cylinders of $80 \mathrm{~mm}$ in length and $50 \mathrm{~mm}$ in diameter referred to as "Plug";

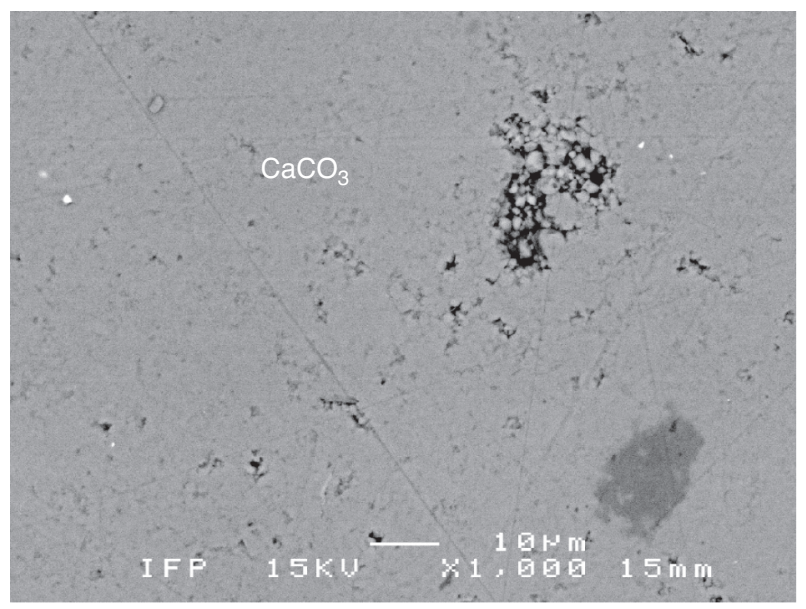

a)

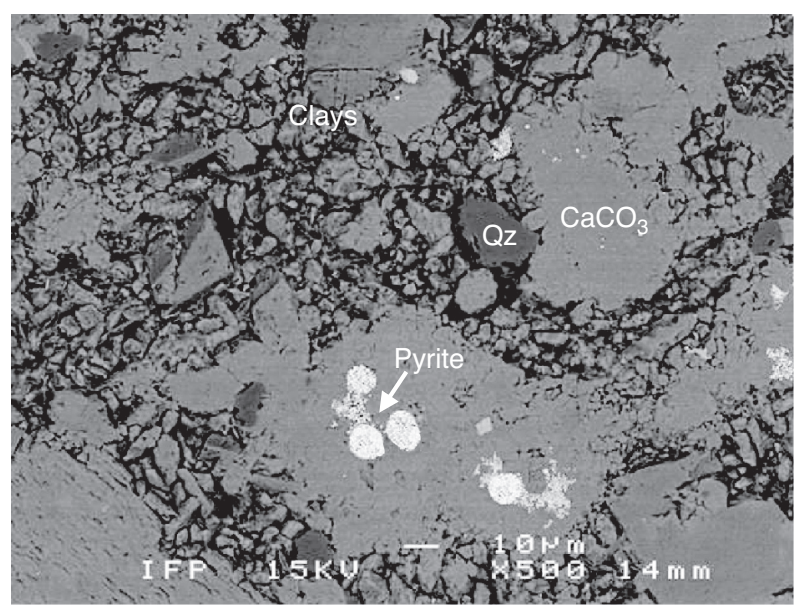

b)

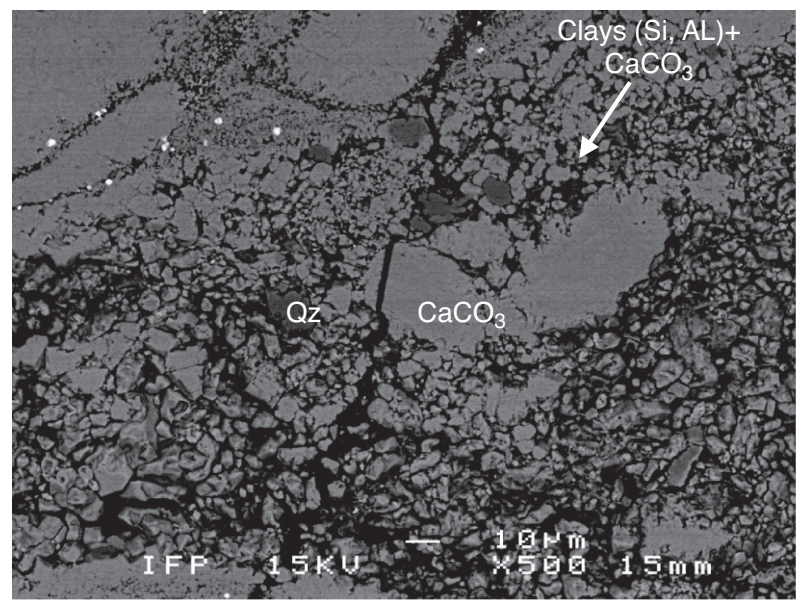

c)

Figure 1

SEM microphotographs representative of the 3 main analyzed facies; a) Sample 106-5-2 cV, facies 4a: lagoon type; b) Sample 107-1-2-cV, facies 3a: shallow water packstone; c) Sample 109-2-1 bV, facies 1c: pre-reef deposits. 

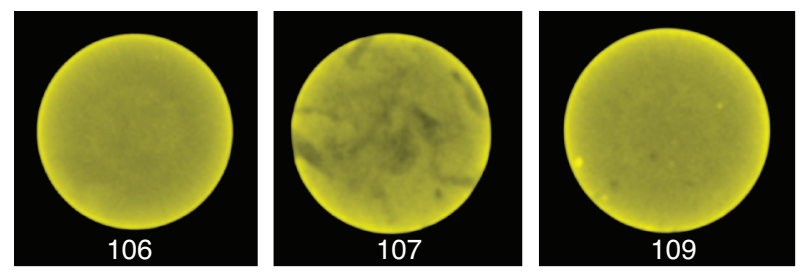

Figure 2

$\mathrm{X}$-ray scan images of 3 samples from each analyzed facies.

- cylinders of $20 \mathrm{~mm}$ in length and $15 \mathrm{~mm}$ in diameter referred to as "Miniplugs";

- crushed samples comprising mm-sized pieces.

\subsection{Laboratory Apparatus and Experimental Procedure}

\subsubsection{Porosity and Porous Structure}

For the plugs, NMR analysis is performed after drying and on brine-saturated samples. Samples were saturated with a $5 \mathrm{~g} / \mathrm{L} \mathrm{NaCl}$ brine. Saturation was obtained by immersing the samples in brine under high pressure (200 bar) during several days Hence, trapped gas bubbles are dissolved into the liquid phase and diffuse out of the samples. Mass difference between dried and saturated sample gives also the porosity. High Pressure Mercury Injection (HPMI) is also performed on companion plugs since it is a destructive method. NMR and HPMI measurements give the porosity and the pore size distribution. Measurements with helium were also used to get the porosity on the same samples. All these techniques are unconfined porosity measurements. Using different techniques to estimate the porosity on tight formations allows the definition of the measurement uncertainties. Discussion on the result differences linked to the applied method is conducted in Section 3.

\subsubsection{Permeability}

Difficulties in measuring permeability in rocks below 10 microDarcy are mainly due to extremely low flow rate. Experiments require therefore an adaptation of the experimental devices used for more permeable rocks. In recent years, both the pulse technique and the steady-state technique have been used to make gas permeability measurements in tight rocks.

\section{Steady-State Permeability on Plugs}

Nitrogen, helium and brine are used for steady-state measurements. Nitrogen steady-state measurements are performed on plugs previously dried at $60^{\circ} \mathrm{C}$ and placed in Hassler cells under hydrostatic confining pressure. Downstream pressure is kept at a constant value (1 to 10 bar) while upstream pressure is fixed at several pressures in order to get several equilibrium points. The confining pressure is maintained at 110 bar or 60 bar to evaluate the impact on permeability. For some samples, brine permeability was performed after complete brine saturation of the samples (obtained as described in the previous section). The confining pressure was increased up to 250 bar in that case. In all cases axial load was equal to the confining pressure. Nitrogen and brine flow rates are measured using a flow meter. Helium flux is diluted in a stream of nitrogen with a known flow rate; the volume fraction of helium in nitrogen is measured by a mass spectrometer which allows calculation of the helium flow rate. This particular arrangement is described in more detail in [8]. Very low flow rates can be measured by this method. Upstream and downstream pressures are measured separately.

\section{Unsteady-State Gas Permeability on Plugs}

Nitrogen is used for unsteady-state measurements. The same apparatus described above is used for the unsteady-state method. Initially, the dried sample is at equilibrium at atmospheric pressure and the outlet of the sample remains closed during the whole experiment duration. A pressure pulse of 30 bar is applied at the inlet and the decrease of the inlet pressure is analyzed and simulated to get the permeability. This method is particularly adapted to tight rocks $(<10$ microD $)$ according to the API Recommended Practices for Core Analysis [4]. The standard interpretation method described by the API is based on an analytical solution that does not allow precise Klinkenberg correction since the pore pressure profile inside the sample is unknown. For this reason a numerical tool had been developed to model the pressure transient response. This numerical simulation allows application of Klinkenberg correction in each grid block and for each time step. The Klinkenberg factor is calculated from an appropriate correlation [9]. The absolute permeability is obtained by history matching.

\section{Gas Permeability on Miniplugs ("Darcygas")}

This method uses pulse pressure testing with air [10,11]. The miniplugs are placed into a cell. The air inside the cell is then quickly compressed using a piston. This overpressure decays with time to a lower pressure as the air moves into the pores within the sample. The pressure transient response is modeled to get the permeability. The main difference with the standard pulse-decay method is that there is no sleeve around the sample. The gas (air) enters on all the surface of the sample. Correction of the Klinkenberg effect is applied using the same correlation for Klinkenberg factor as for unsteady-state measurements on plugs.

\subsubsection{Threshold Capillary Pressure $\left(\boldsymbol{P}_{t h}\right)$}

The capillary sealing efficiency of a rock sample can be defined in many ways as discussed in [12]. Here we shall define the 
threshold capillary pressure as the minimum pressure to force a non-wetting fluid into a wetting fluid-saturated sample, without necessarily creating a continuous path for the nonwetting fluid through the sample. This quantity can be measured in several different ways $[6,12]$. Three of them are used and compared here, with the notable exception of the residual capillary pressure approach proposed by [12]. This approach is indeed suspected of underestimation ot the effective threshold pressure [6].

\section{Estimation by High Pressure Mercury Injection (HPMI)}

Threshold capillary pressure is first estimated by deriving the in situ threshold capillary pressure $\left(P_{t h}\right)$ value from a mercury porosimetry curve, knowing the values of the Interfacial tension (IFT) and the contact angle for the fluid system and the rock considered. As shown in Figure 3, the intersection of the tangents of the curve of saturation versus logarithm of the mercury injection pressure gives the pressure value at which the mercury significantly penetrates the sample. The subjective choice of the tangents as well as the lack of data to convert the mercury based threshold $P_{t h}$ for a $\mathrm{CO}_{2} /$ brine fluid system makes the threshold capillary pressure value uncertain. The chosen values for the fluid pair properties are given in Table 2 and based on published data [13, 14].

Another shortcoming of the mercury porosimetry approach is the lack of confining pressure. Petrophysical properties of some low-permeability rock samples may be quite sensitive to the confining stress [15]. For this reason, it is necessary to measure the threshold capillary pressure on the samples at in situ conditions. Two methods are used in this study.

TABLE 2

Interfacial tension (IFT) and contact angle values used for the different fluid pairs

\begin{tabular}{l|c|c|c}
\hline & $\mathrm{Hg} / \mathrm{air}$ & $\mathrm{N}_{2} /$ brine & $\mathrm{CO}_{2} /$ brine \\
\hline Interfacial tension $(\mathrm{dyn} / \mathrm{cm})$ & 480 & 78 & 26 \\
\hline Contact angle $\left(^{\circ}\right)$ & 140 & 20 & 0 \\
\hline
\end{tabular}

\section{The Step-by-Step Approach (Standard Approach)}

The standard approach consists of a step-by-step increase of the gas pressure at the inlet face of a sample fully saturated with brine while recording the brine production or the pressure rise at the outlet [16]. This approach can be conducted under in situ conditions and is also very simple to interpret since it relies on the definition of the threshold capillary pressure. However, the onset of brine production is generally hard to detect accurately because the brine production rates just above the threshold capillary pressure are very small. These experimental difficulties can contribute to an overestimation of the threshold $P_{t h}$ value if the pressure step is not long enough.

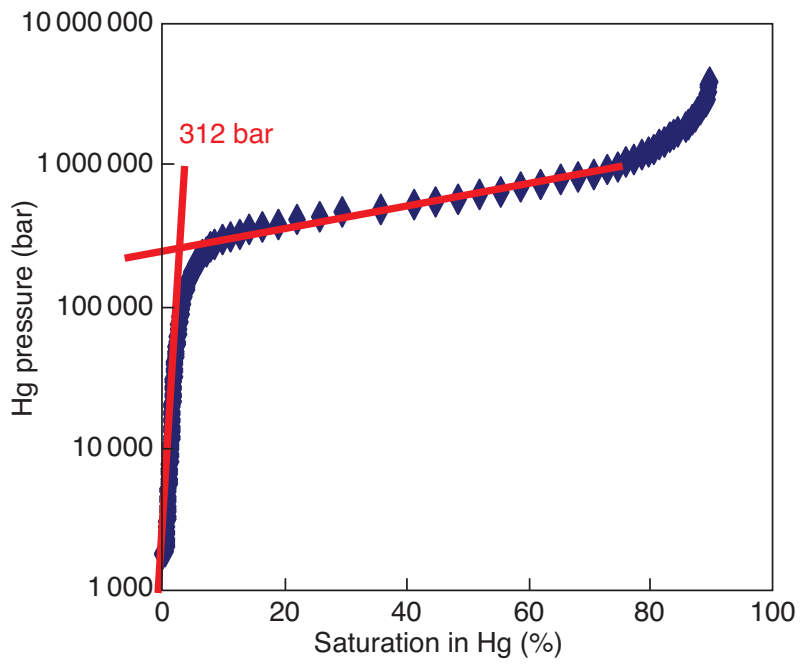

Figure 3

Example of a mercury injection curve in a sample. The threshold capillary pressure can be estimated using the tangents intersection method.

\section{The Dynamic Threshold Capillary Pressure Approach}

From a "dynamic" point of view, $P_{t h}$ can also be considered as a pressure difference between the non-wetting and the wetting phases that does not contribute to the flow [6]. Consider a rock sample initially saturated with brine and put under flowing conditions with addition of a non-wetting fluid by applying a constant overall pressure difference $\left(\Delta P_{t}\right)$, higher than the estimated $P_{t h}$ value, across the sample. The non-wetting fluid therefore gradually invades the sample The total pressure drop, $\Delta P_{t}$, can then be divided into several parts, as illustrated by Figure 4:

$$
\Delta P_{t}=\Delta P_{n w}+P_{t h}+\Delta P_{w}
$$

where $\Delta P_{n w}$ is the pressure drop in the non-wetting fluid invaded region, $\Delta P_{w}$ is the pressure drop in the virgin region and $P_{t h}$ is the capillary pressure jump at the front (also equal to the capillary threshold pressure).

At the start of the non-wetting fluid penetration, two assumptions can be made:

- the pressure drop in the non-wetting invaded region can be neglected $\left(\Delta P_{n w}\right.$ equal to zero). This results from the limited extent of this region at the start of the injection (as well as the much lower viscosity of the gas phase);

- the pressure drop in the virgin region, that generates a counter pressure in the brine phase, can be deduced using the effective brine production rate that is recorded at the outlet from the Darcy's law. It is then possible to determine directly the threshold capillary pressure value using the expression:

$$
P_{t h}=\Delta P_{t}-\Delta P_{w}
$$




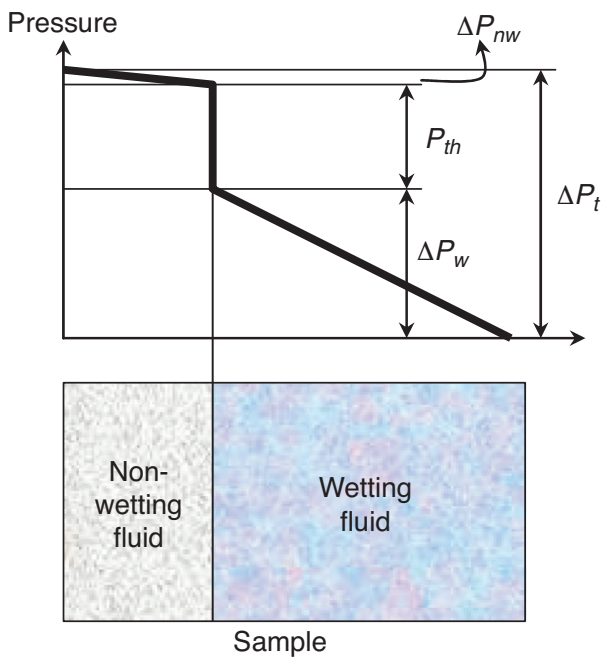

Figure 4

Pressure profile in the sample during dynamic measurement of capillary threshold pressure.

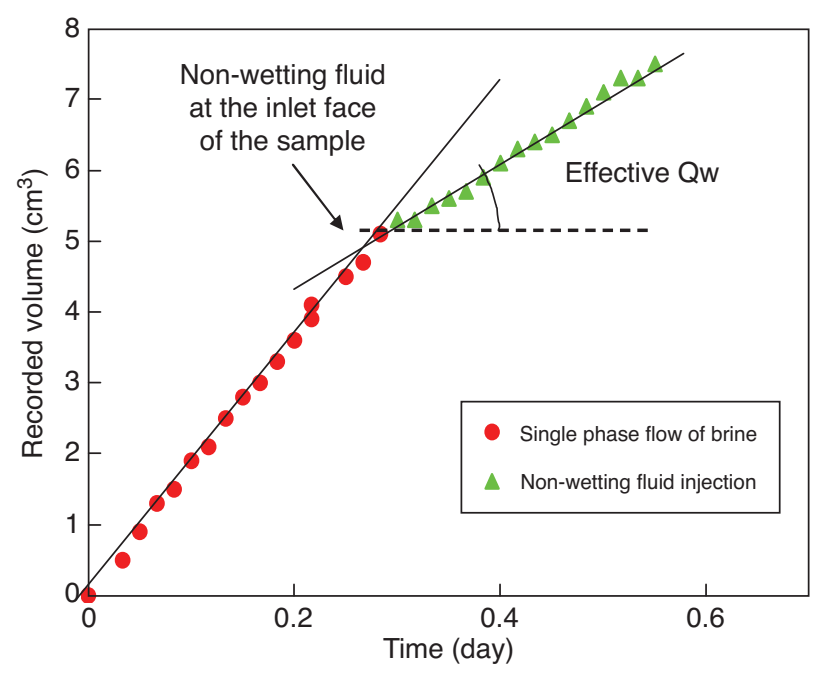

Figure 5

Typical production curve recorded at the outlet with a break in the slope.

Figure 5 shows the evolution of the brine production during a test. The initial slope corresponds to the single phase flow of brine through the sample. As soon as the non-wetting fluid gets to the inlet face of the core, a significant decrease of the slope (brine flow rate) is recorded due to the capillary pressure jump at the non-wetting phase front.

Experimental Set-up for Dynamic $P_{\text {th }}$ Measurements

The experimental apparatus used to conduct the test is composed of a core holder, a regulated pump to inject the non-wetting fluid under controlled pressure conditions, a differential pressure sensor and a very accurate capacitancebased detector to record the brine production. The core holder is placed in an oven under confining pressure to create in situ reservoir conditions.

\section{PETROPHYSICAL CHARACTERISTICS OF THE DOGGER FORMATION CAPROCKS (PARISIAN BASIN)}

\subsection{Porosity and Porous Structure}

The unconfined porosity was measured using different techniques on the same sample to allow comparison and to estimate measurement uncertainty. The unconfined porosity measured on the cores $\mathrm{CH} 106, \mathrm{CH} 107$ and $\mathrm{CH} 109$ vary from 2 to $9 \%$ (Fig. 6). Discrepancies found between the different methods are in a large part due to the difficulty to obtain a fully saturated or a perfectly dried sample with this kind of tight materials. This explains the lower porosity measured by weight difference. NMR and HPMI are two techniques which access a large part of the porous network. Mercury cannot penetrate the smallest pores (under $3 \mathrm{~nm}$ ), thus a higher porosity by NMR could be expected. The presence of residual gas prevents full sample saturation and so explains the very similar results obtained with these two methods. Helium pycnometry is supposed to access almost the entire porous network, and thus to give the highest porosity results. This was the case with the studied samples, but it has to be kept in mind that the very low porosity, and therefore the small difference between skeletal and apparent densities of these materials induced high uncertainties with this measurement technique.

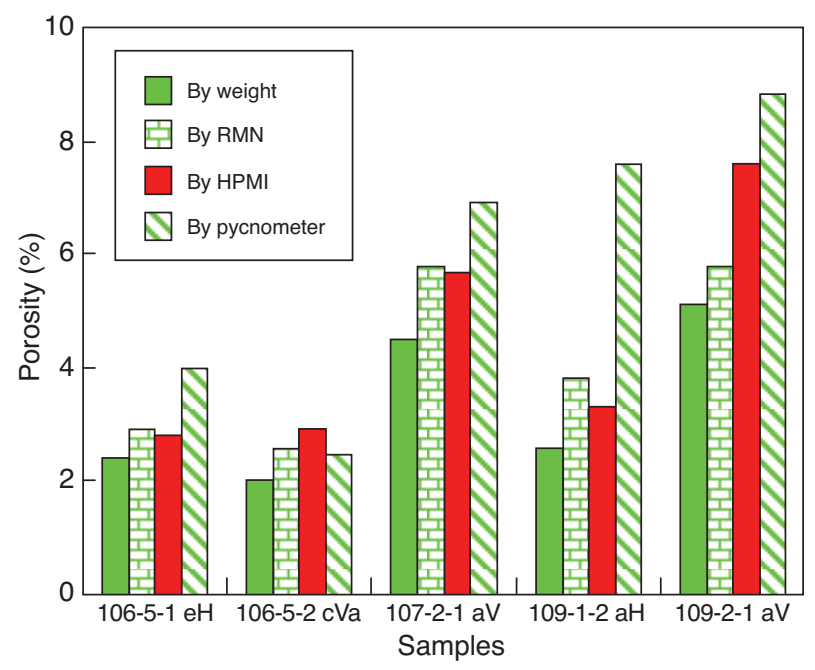

Figure 6

Porosity results using different methods on the same sample: porosity by weight differences, NMR, HPMI, and helium pycnometry. 

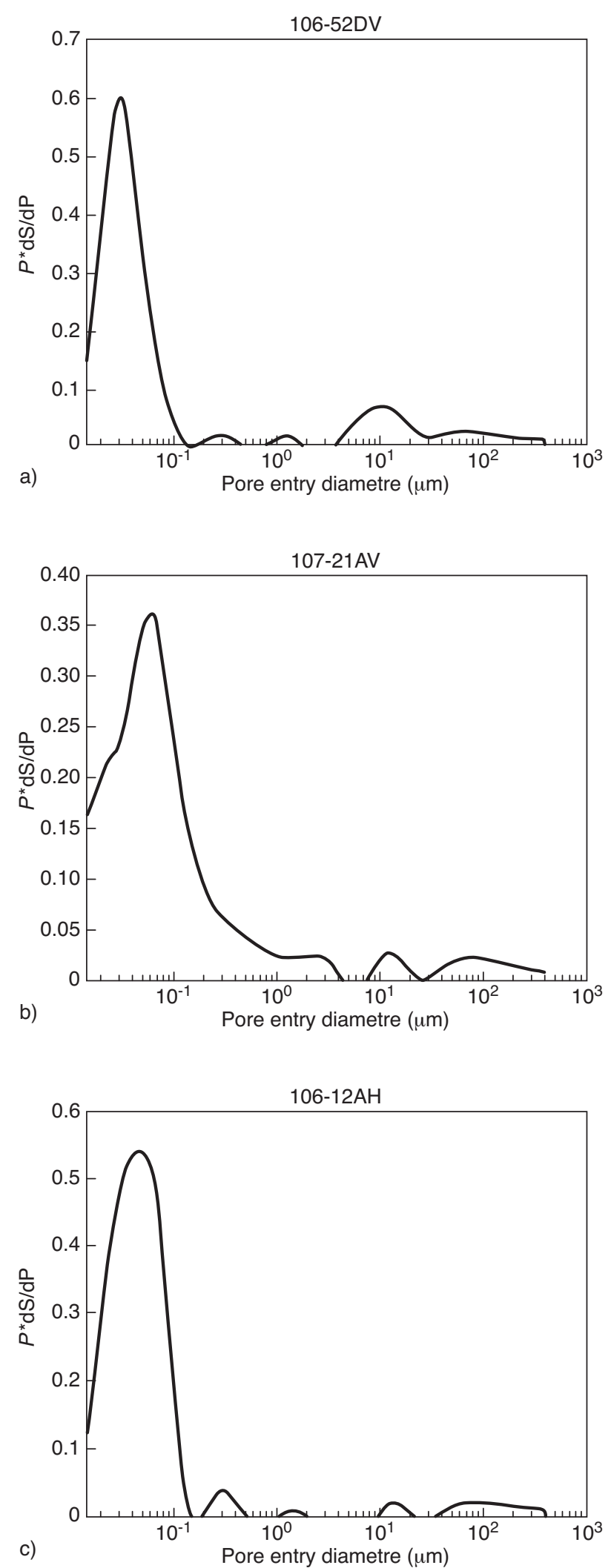

Figure 7

Pore throat size distribution for the 3 different facies from High Pressure Mercury Injection (HPMI).

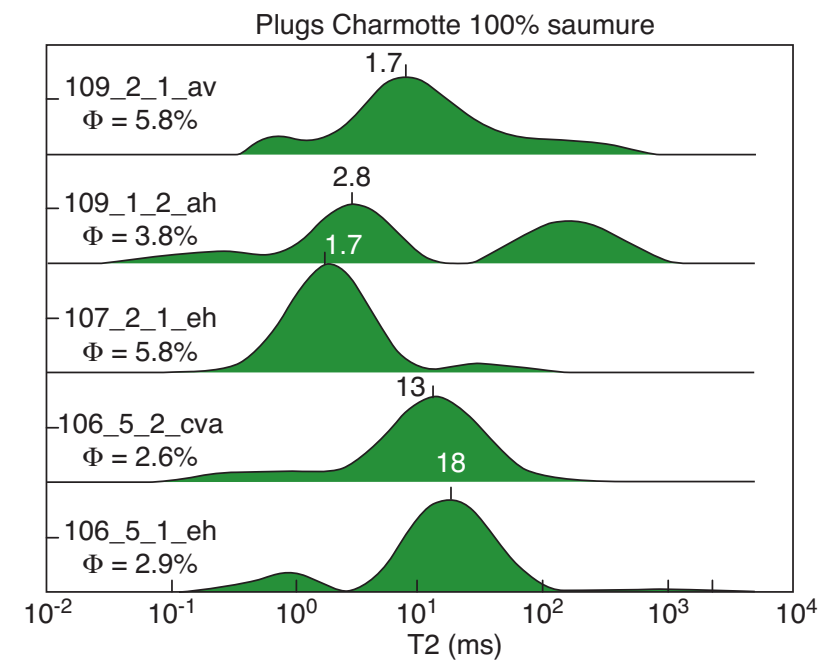

Figure 8

NMR T2 distribution of brine-saturated samples from CH106, CH107 and CH109.

The carbonates from cores $\mathrm{CH} 107$ and $\mathrm{CH} 109$ (transition zone and Dalle Nacrée formations) are more porous than the tight carbonates from Comblanchien (CH106). Pore throat size is very small for all facies $(0.05 \mu \mathrm{m})$ and generally of unimodal distribution (Fig. 7). However T2 distribution from NMR gives a bimodal response for sample 109-1-2aH (Fig. 8).

\subsection{Porosity and Petrographic Study}

The samples for which porosity and permeability were measured were also studied petrographically by thin section. Table 3 shows the comparison of the porosity values directly from measurements (from HPMI, NMR or helium) but also porosity visual estimation from thin sections. HPMI, NMR or helium methods give very close results and were therefore gathered in one column $\left(\Phi^{(1)}\right)$ which gives an indication of the uncertainty range on porosity (except for the sample 109-1-2aH where a significant gap between the porosities is attributed to one false measurement or to facies heterogeneities since some measurements are performed on neighbouring samples).

Porosities obtained from image analysis are also given in column $\Phi^{(2)}$. They generally match reasonably well the direct measurements.

When the difference is more than $2 \mathrm{PU}$ (samples 109-2-1 and 107-2-1), it is probably due to facies heterogeneities (unequal cementation around grains or unconnected porosities for example) since measurements are performed on neighboring samples and optical estimation of the porosity is made on plan view. Centimeter scale heterogeneity of facies 3 and 1 is confirmed by petrographic analysis of the samples (cf. Sect. 1). 
TABLE 3

Comparison between unconfined porosity measurements 1) by helium, HPMI and/or NMR, and,

2) porosity from image analysis on thin sections

\begin{tabular}{c|c|c|c|c}
\hline Sample & Depth m/RT & Facies & $\Phi^{(1)} \%$ & $\Phi^{(2)} \%$ \\
\hline $106-5-1 \mathrm{eH}$ & 1911.39 & $4 \mathrm{~b}$ & $2.8-4.0$ & $1-2$ \\
\hline $106-5-2 \mathrm{cV}$ & 1910.95 & $4 \mathrm{a}$ & $2.0-2.6$ & $1-2$ \\
\hline $106-5-2 \mathrm{dV}$ & 1910.5 & $4 \mathrm{~b}$ & $2.5-2.9$ & $3-4$ \\
\hline $107-1-2 \mathrm{cV}$ & 1958.87 & $3 \mathrm{a}$ & 3.8 & $5-6$ \\
\hline $107-2-1 \mathrm{aV}$ & 1959.12 & $3 \mathrm{c}$ & $3.8-5.8$ & $7-8$ \\
\hline $109-1-2 \mathrm{aH}$ & 2000.0 & $1 \mathrm{~b}$ & $3.3-7.6$ & $<5$ \\
\hline $109-2-1 \mathrm{aV}$ & 2006.73 & $1 \mathrm{c}$ & $7.6-8.8$ & 5 \\
\hline $109-2-1 \mathrm{bV}$ & 2006.56 & $1 \mathrm{c}$ & 5.9 & 5 \\
\hline $109-2-1 \mathrm{eV}$ & 2006.46 & $1 \mathrm{c}$ & 7.6 & 5 \\
\hline $109-2-2 \mathrm{aH}$ & 2006.28 & $1 \mathrm{~b}$ & 3.3 & $<5$ \\
\hline
\end{tabular}

\subsection{Single-Phase Permeability}

The permeability measured using the 3 different methods (described above) on the samples $\mathrm{CH} 106, \mathrm{CH} 107$ and CH109 varies from 0.03 to 20 microDarcy (Tab. 4, Fig. 9). For the same facies and using the same measurement technique, the samples can exhibit a permeability difference of two magnitudes (e.g. 106-5-1 versus 106-5-2 and 109-1-2 versus 109-2-1), showing a large variability of flowing properties at a small scale probably due to rock heterogeneities.

For the same sample, the fact that water permeability is lower than Klinkenberg-corrected gas permeability is not surprising. This is partly due to the difference in effective stress (gas permeability was performed under 110 bar of confining pressure while water permeability was performed under 250 bar of confining pressure) and essentially due to the fluid effect. Indeed, the same gap is systematically found in the literature and is enhanced at this low level of permeability [9].

Permeability measured by the Darcygas technique is quite low compared to the other values despite the fact that this measurement is performed under unconfined conditions. The differences found between the methods are not yet fully explained [11] but may be linked to an enhanced Klinkenberg effect. The Darcygas technique is still in improvement in IFP laboratory.

For such low permeability levels, the use of different techniques allows the evaluation of the uncertainties attached to the measurements. Various hypotheses explaining the permeability differences between the methods (experimental artifacts, stress effects, Klinkenberg correction accuracy, fluid geochemistry effects) are currently being tested in the IFP petrophysical laboratory.
TABLE 4

Permeability results (MicroDarcy). $P_{C}=$ Confining pressure. All the $K_{g}$ values are corrected from Klinkenberg effects.

\begin{tabular}{c|c|c|c|c}
\hline Sample & $\begin{array}{c}K_{g} \text { steady } \\
\text { state on plug } \\
P_{C}=110 \text { bar }\end{array}$ & $\begin{array}{c}K_{g} \text { unsteady } \\
\text { state on plug } \\
P_{C}=110 \text { bar }\end{array}$ & $\begin{array}{c}K_{w} \\
\text { on plug } \\
P_{C}=250 \text { bar }\end{array}$ & $\begin{array}{c}K_{g} \text { Darcygas } \\
\text { on miniplug } \\
P_{C}=0 \text { bar }\end{array}$ \\
\hline $106-5-1$ & $3.7^{*}$ & 6 & 0.3 & 0.4 \\
\hline $106-5-2$ & $0.4^{*} / 0.5 * *$ & 0.4 & 0.1 & 0.1 \\
\hline $107-1-4$ & $2 * *$ & - & - & - \\
\hline $107-2-1$ & $1.5^{*} / 2.5^{* *}$ & 2 & 0.05 & 0.06 \\
\hline $109-1-2$ & $0.2^{*}$ & 0.3 & 0.03 & 0.2 \\
\hline $109-2-1$ & $12.7^{* *}$ & 20 & 3.7 & 1 \\
\hline
\end{tabular}

* Gas used is nitrogen. ** Gas used is helium

\subsection{Permeability and Stress Effect}

Unsteady-state permeability measurements were performed at different effective stresses by varying confining pressure from 60 to 110 bar and keeping the same pore pressure (15 bar on average). As seen in Figure 10, the effective stress change of 50 bar does not produce a strong effect on the permeability that is mostly within measurement uncertainties in the case of the least permeable samples.

\subsection{Threshold Capillary Pressure Estimation from HPMI}

Threshold capillary pressure is first estimated from HPMI. Table 5 summarizes the estimated values of threshold

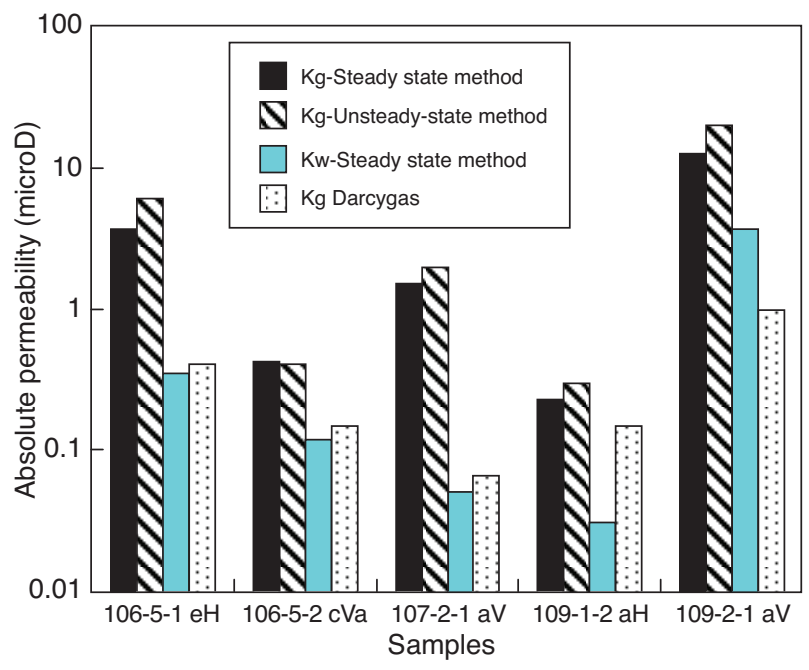

Figure 9

Comparison of permeability values obtained by different methods. 


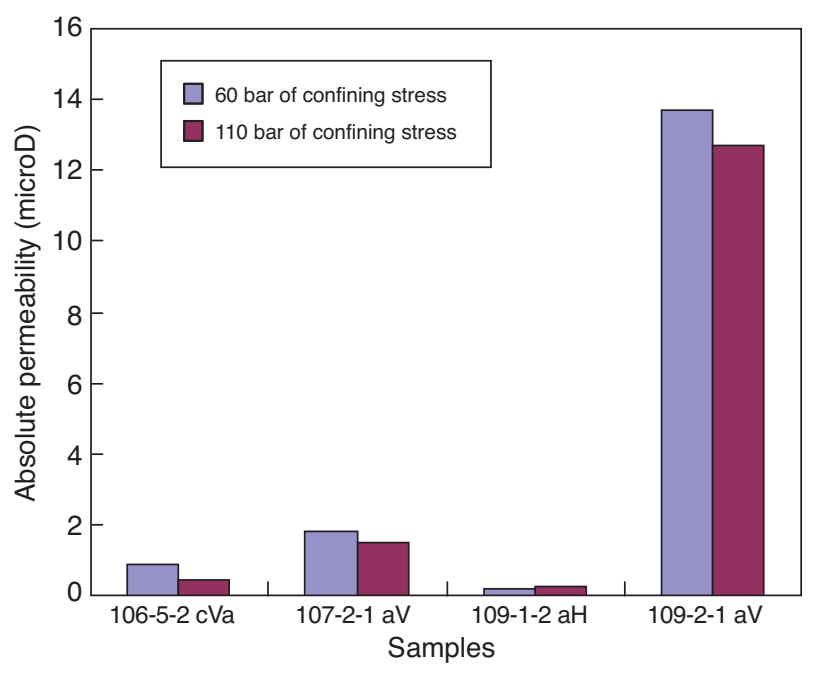

Figure 10

Klinkenberg-corrected gas permeability measurements performed under 60 and 110 bar of confining pressure.

capillary pressure from HPMI for the fluid couples $\mathrm{N}_{2} /$ brine and $\mathrm{CO}_{2}$ /brine (interfacial tension and contact angle used are given in Tab.2).

TABLE 5

Threshold capillary pressure estimations from HPMI measurements with interfacial tension and contact angle conversions

\begin{tabular}{c|c|c}
\hline Sample & $P_{t h} \mathrm{~N}_{2} /$ brine (bar) & $P_{t h} \mathrm{CO}_{2} /$ brine (bar) \\
\hline $106-5-1 \mathrm{bV}$ & 69 & 22 \\
\hline $106-5-2 \mathrm{dV}$ & 44 & 16 \\
\hline $107-1-2 \mathrm{cV}$ & 35 & 12 \\
\hline $107-2-1 \mathrm{aV}$ & 15 & 5 \\
\hline $109-1-2 \mathrm{aH}$ & 25 & 9 \\
\hline $109-2-1 \mathrm{cV}$ & 2.3 & 0.8 \\
\hline $109-2-1 \mathrm{eV}$ & 1.2 & 0.4 \\
\hline $109-2-2 \mathrm{aH}$ & 30 & 10 \\
\hline
\end{tabular}

\subsection{Threshold Capillary Pressure from Direct Measurements with $\mathrm{N}_{2}$}

Threshold capillary pressure measurements are then performed using the dynamic method. This method, accurate and efficient for the most porous sample (109-2-1 aV) is subject to uncertainties for samples with lower porosity (3 to $5 \%$ ) and lower permeability (very low flow rates and change in flow rates hard to detect). When the dynamic method is found inappropriate (i.e. low flow rate is recorded and changes are difficult to identify) the standard approach is performed. Table 6 compares the different $P_{t h}$ values estimated from HPMI and directly measured with $\mathrm{N}_{2}$. HPMI yields significantly larger values than direct measurements, but both are somehow correlated (the larger the $P_{t h}$ from HPMI, the larger the direct measurement). The literature reports contradictory results on the comparison of both methods, ranging from close agreement to total decorrelation [12]. At any rate, there are sound reasons why the HPMI values should be taken with caution ( $c f$. Sect. 2.2). This is why direct measurements on plugs with $\mathrm{N}_{2}$ are regarded as reference values to use taking into account $\mathrm{CO}_{2}$ effect (lower IFT than $\mathrm{N}_{2}$ which may decrease the threshold pressure) and in situ stress state corrections.

TABLE 6

Summary of $P_{t h}$ results by HPMI and by direct measurements with $\mathrm{N}_{2}$

\begin{tabular}{c|c|c}
\hline & HPMI & Direct tests on plugs \\
\hline Sample & $P_{t h} \mathrm{~N}_{2} /$ brine (bar) & $P_{t h} \mathrm{~N}_{2} /$ brine $(\mathrm{bar})$ \\
\hline $106-5-1 \mathrm{bV}$ & 69 & \\
\hline $106-5-2 \mathrm{dV}$ & $44 / 30$ & $15<P_{t h}<20$ \\
\hline $107-1-2 \mathrm{cV}$ & 35 & \\
\hline $107-2-1 \mathrm{aV}$ & 15 & $5<P_{t h}<10$ \\
\hline $109-1-2 \mathrm{aH}$ & 25 & 15 \\
\hline $109-2-1 \mathrm{aV}$ & & 4.5 \\
\hline $109-2-1 \mathrm{cV}$ & 2.3 & \\
\hline $109-2-1 \mathrm{eV}$ & $1.2 / 1.9$ & \\
\hline $109-2-2 \mathrm{aH}$ & 30 & \\
\hline
\end{tabular}

\subsection{Threshold Capillary Pressure: Study of the Impact of $\mathrm{CO}_{2}$ Versus Neutral Gas $\left(\mathrm{N}_{2}\right)$}

In order to evaluate the influence of the gas type on the threshold capillary pressure, tests were performed on carbonated caprock from a temporary gas storage field. This lithology is selected because it has the right characteristics (higher porosity) to obtain better contrast in flow rates and shorter saturation phase duration (experiments of a few days compared to more than 1 month for Charmottes samples). This sample has a permeability of 1 microDarcy under 180 bar of mean effective stress. Measurements were only performed with the dynamic methods and in two steps:

- sample saturation with $20 \mathrm{~g} / \mathrm{L}$ brine and threshold capillary pressure measurements with nitrogen at 200 bar of mean effective stress and $50^{\circ} \mathrm{C}$ (Fig. 11). The value of threshold capillary pressure found with $\mathrm{N}_{2}$ was recalculated changing IFT and contact angle to give a value for the fluid couple $\mathrm{CO}_{2}$ /brine, as we have done in the previous experiment on Charmottes samples; 


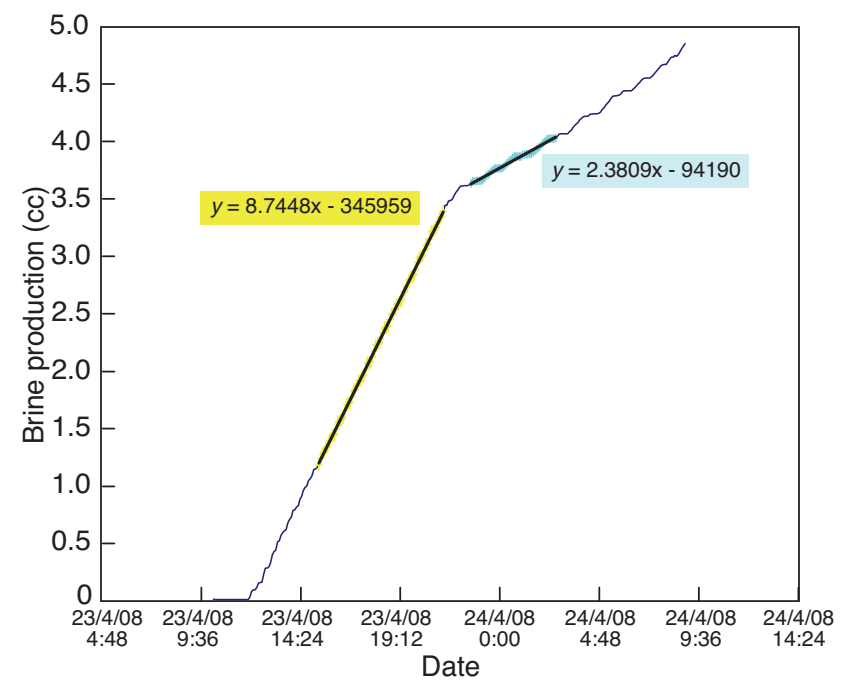

Figure 11

Brine production versus time during $P_{t h}$ measurement with the dynamic method using $\mathrm{N}_{2}$ as intruding fluid. Slope change is due to the capillary pressure drop when $\mathrm{N}_{2}$ enters the sample.

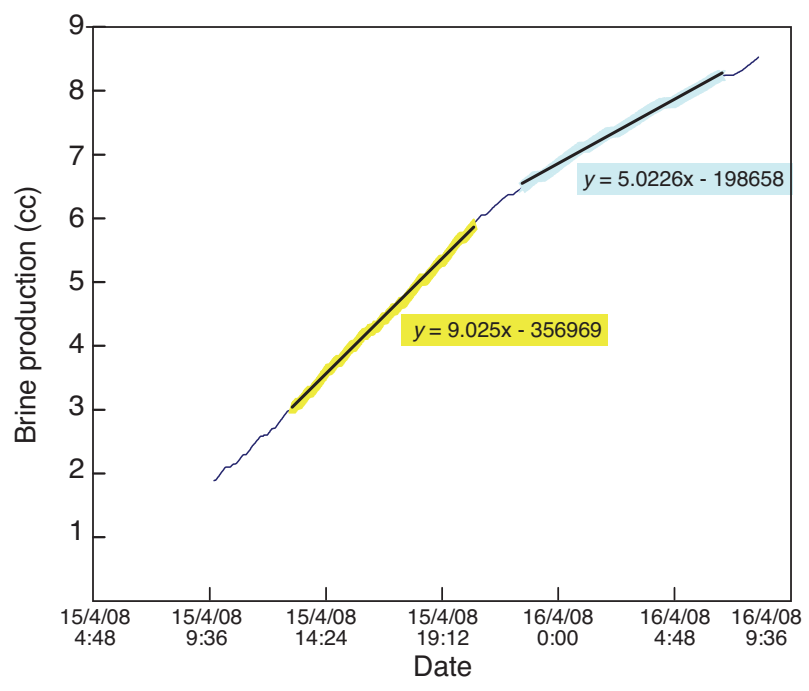

Figure 12

Brine production versus time during $P_{t h}$ measurement with the dynamic method using $\mathrm{CO}_{2}$ as intruding fluid. Slope change is due to the capillary pressure drop when $\mathrm{CO}_{2}$ enters the sample.
- sample resaturation with $20 \mathrm{~g} / \mathrm{L}$ brine and threshold capillary pressure measurements with supercritical $\mathrm{CO}_{2}$ at 200 bar of mean effective stress and $50^{\circ} \mathrm{C}$ (Fig. 12).

Table 7 shows the results of this study. The third value is calculated from the first $P_{t h}$ value with $\mathrm{N}_{2}$, multiplied by the ratio of IFT and contact angle between $\mathrm{N}_{2}$ /brine and $\mathrm{CO}_{2}$ /brine. The threshold capillary pressure obtained with a direct measurement with $\mathrm{CO}_{2}$ is 8.4 bar, which is about twice the recalculated value from measurement with $\mathrm{N}_{2}$.

\section{TABLE 7}

Comparison of $P_{t h}$ measurements on the caprock sample $X$ with different fluids. The last value is derived from the first $P_{t h}$ with $\mathrm{N}_{2}$

\begin{tabular}{c|c|c|c}
\hline & $\mathrm{N}_{2} /$ brine & $\mathrm{CO}_{2} /$ brine & $\mathrm{CO}_{2} /$ brine \\
Sample X & $T=50^{\circ} \mathrm{C}$ & $T=50^{\circ} \mathrm{C}$ & $T=50^{\circ} \mathrm{C}$ \\
& $\begin{array}{c}P_{C}=200 \mathrm{bar} \\
(1)\end{array}$ & $\begin{array}{c}P_{C}=200 \mathrm{bar} \\
P_{C}=200 \mathrm{bar} \\
\text { calculated from (1) }\end{array}$ \\
\hline$P_{t h}$ (bar) & 12.5 & 8.4 & 4.5 \\
\hline
\end{tabular}

The study reported in [17] also presents direct measurements of a capillary threshold (actually the residual capillary pressure) for nitrogen and $\mathrm{CO}_{2}$. The results suggest that the actual measured values for $\mathrm{CO}_{2}$ were also larger by a factor of approximately 2 than the values deduced from the $\mathrm{N}_{2}$ data and the Laplace law.
These results have consequences on the accuracy of the results for the Charmottes samples. The $P_{t h}$ for the $\mathrm{CO}_{2}$ /brine system derived from $P_{t h}$ measurement with $\mathrm{N}_{2}$ may be underestimated. The underestimation of IFT for the fluid couple $\mathrm{CO}_{2}$ /brine at $P, T$ conditions may also be the origin of the discrepancy between the measured and the recalculated values. However it is difficult to conclude from a single measurement. Other tests are necessary to understand the gaseous and supercritical $\mathrm{CO}_{2}$ effect on the threshold capillary pressure of caprocks. Another important effect to be borne in mind is the modification of rock properties by contact with $\mathrm{CO}_{2}$, as shown in [18]. This work reports a significant reduction of the sealing efficiency of samples by repeated $\mathrm{CO}_{2}$ breakthrough experiments. This effect has however not been investigated in the present study, the primary aim of which was characterization of unaltered caprocks.

\section{DISCUSSION, CONCLUSIONS AND PERSPECTIVES}

The purpose of this study was to evaluate the confining properties of carbonated caprocks in regard with $\mathrm{CO}_{2}$ storage. Several parameters, such as porosity, permeability and threshold capillary pressure were thus measured using different and complementary methods:

- single-phase permeabilities were obtained using special techniques for measurement of tight formations. The results can differ by a factor of ten; 
- taking as references unsteady state $K_{g}$ measurements on plugs, permeability varies from 0.3 to 20 microDarcy, related to facies variations;

- the measured $P_{t h}$ are very variable and sometimes very low ( $<1$ bar). Therefore, we conclude that $\mathrm{CO}_{2}$ migration may occur in such rocks. Defining a minimum threshold pressure is difficult because the overpressure on the $\mathrm{CO}_{2}$ phase depends on the injection rate, reservoir permeability and thickness. However, a range of 10 to 20 bar may be necessary in most situations at supercritical conditions;

- if migration is likely to occur, the permeability becomes a critical criteria. In general, the measured permeabilities are around 1 microDarcy. With such values and using two phase flow simulations [19], it can be shown that the $\mathrm{CO}_{2}$ migration will be limited to a few meters when the overpressure is maintained during a few hundred years. For carbonated rocks, a low porosity may also play an important role. The "Tight Comblanchien" ( $\mathrm{CH} 106$ core) is characterized by the smallest porosity and by the least connected porosity among the 3 characterized facies. Indeed this facies of lagoon type exhibits very low porosity (always below 5\% and more frequently of 1-2\%) in Charmottes cores. However, these limestones are currently dolomitized in the eastern part of the Picoref area [7] which rises the microporosity of these tight levels to more than $5 \%$;

- in this project, other threshold pressure tests were performed on a carbonated caprock of an actual gas storage field. The results of these tests show that threshold capillary pressure obtained with a direct measurement with $\mathrm{CO}_{2}$ is twice the predicted value from measurement with $\mathrm{N}_{2}$. This suggests two hypotheses: either the IFT has a lower impact than predicted on the threshold pressure or IFT for the $\mathrm{CO}_{2}$ /brine system is underestimated. However these hypotheses are based only on one test. More experimental studies are needed to confirm these results;

- in the time available for this research project, overburden stress effects on threshold capillary pressure have not been studied and quantified. $P_{t h}$ tests being very time-consuming due to long time brine saturation of the samples. Nevertheless complementary measurements should be performed at different stress states. Relative permeability measurements for the fluid couple $\mathrm{CO}_{2}$ /brine at in situ conditions are also very time consuming and hard to perform on this type of rock but are necessary to complete caprock petrophysics characterization;

- at larger scale, matrix properties of a potential caprock must be completed by a structural study of the basin in order to be able to homogenize the petrophysical characteristics of the caprocks.

\section{ACKNOWLEDGMENTS}

The authors gratefully thank Toreador Resources Corporation to have furnished the core samples and for permission to publish these results. We wish to thank the ANR for supporting this project. The authors also acknowledge J. Ginatta, F. Norrant and J. Guelard for their contribution to the experimental work. Finally we would like to acknowledge M. Fleury and D. Broseta for fruitful discussions.

\section{REFERENCES}

1 International Energy Agency (2004) Prospects for $\mathrm{CO}_{2}$ Capture and Storage, $O E C D / I E A$, Paris.

2 Orr F.M. Jr (2004) Storage of Carbon Dioxide in Geologic Formations, SPE 88842.

3 Horseman S.T., Harrington J.F., Sellin P. (1999) Gas migration in clay barriers, Eng. Geol. 54, 139-149.

4 API (1998) Recommended Practices for Core Analysis, Recommended Practice $\mathbf{4 0 .}$

5 Klinkenberg L.J. (1941) The permeability of Porous Media to Liquids and Gases: Drilling and production Practice, American Petroleum Institute, 200-213.

6 Egermann P., Lombard J.M., Bretonnier P. (2006) A fast and accurate method to measure threshold capillary pressure of caprocks under representative conditions, SCA2006 A46.

7 Lasseur E., Le Nindre Y.M. (2008) Pétrologie sédimentaire du Dogger carbonaté du secteur Picoref (Bassin de Paris). Estimation des propriétés de couverture, Rapport final $B R G M / R P-F R$.

8 Boulin P.F., Anglo-Jaramillo R., Daian J.F., Talandier J., Berne Ph. (2008) Experiments to estimate gas intrusion in Callovo-Oxfordian argillites, Phys. Chem. Earth Pt A/B/C 33, S225-S230.

9 Jones F.O., Owens W.W. (1980) A Laboratory Study of Low-permeability Gas Sands, J.Petrol.Technol. 1631-1640.

10 Luffel D.L., Hopkins C.W., Shettler P.D. (1993) Matrix Permeability Measurements of Gas Productive Shales, SPE 26633.

11 Carles P., Egermann P., Lenormand R., Lombard J.M. (2007) Low permeability measurements using steady-state and unsteady-state methods, paper SCA2007-07 presented at the International Symposium of the Society of Core Analysts, Calgary, 10-12 September 2007.

12 Hildenbrand A., Schlömer S., Krooss B.M. (2002) Gas breakthrough experiments on fine-grained sedimentary rocks, Geofluids 2, 3-23.

13 Chalbaud C., Robin M., Egermann P. (2006) Interfacial Tension Data and Correlations of Brine $/ \mathrm{CO}_{2}$ Systems under Reservoir Conditions, SPE 102918.

14 Chiquet P., Daridon J.L., Broseta D., Thibeau S. (2007) $\mathrm{CO}_{2}$ /water interfacial tensions under pressure and temperature conditions of $\mathrm{CO}_{2}$ geological storage, Energ. Convers. Manage. 48, 736-744.

15 Shanley K.W., Cluff R.M., Robinson J.W. (2004) Factors controlling prolific gas production from low-permeability sandstone reservoirs: implications for resource assessment, prospect development and risk analysis, AAPG Bull. 88, 1083-1121. 
16 Al-Bazali T.M., Zhang J., Chenevert M.E., Sharma M.M. (2008) Capillary entry pressure of oil-based muds in shales: the key to the success of oil-based muds, Energ. Source. Part A 30, 297-308.

17 Hildenbrand A., Schlömer S., Krooss B.M., Littke R. (2004) Gas breakthrough experiments on pelitic rocks: comparative study with $\mathrm{N}_{2}, \mathrm{CO}_{2}$ and $\mathrm{CH}_{4}$, Geofluids 4, 61-80.

18 Wollenweber J., Alles S., Kronimus A., Busch A., Stanjek H., Krooss B.M. (2009) Caprock and overburden processes in geological $\mathrm{CO}_{2}$ storage: an experimental study on sealing efficiency and mineral alterations, Energy Procedia 1, 3469-3476.
19 Bildstein O., Kervévan C., Lagneau V., Delaplace P., Crédoz A., Audigane P., Perfetti E., Jullien M. (2009) Integrative modeling of caprock integrity in the context of $\mathrm{CO}_{2}$ storage: evolution of transport and geochemical properties and impact on performance and safety assessment, submitted to OGST.

Final manuscript received in November 2009 Published online in May 2010 or distributed for profit or commercial advantage and that copies bear this notice and the full citation on the first page. Copyrights for components of this work owned by others than IFP must be honored. Abstracting with credit is permitted. To copy otherwise, to republish, to post on servers, or to redistribute to lists, requires prior specific permission and/or a fee: Request permission from Documentation, Institut français du pétrole, fax. +33147527078 , or revueogst@ifp.fr. 